\title{
Laser based manufacturing of titanium aluminides
}

\author{
Silja-Katharina Rittinghaus ${ }^{1}$, Veronica Rocio Molina Ramirez ${ }^{1}$, Andreas Vogelpoth ${ }^{1}$, Ulrike Hecht ${ }^{2}$, Janett Schmelzer ${ }^{3}$ \\ ${ }^{1}$ Fraunhofer Institute for Laser Technology ILT, Steinbachstraße 15, 52074 Aachen \\ 2 Access e.V., Intzestraße 5, 52072 Aachen \\ 3 Otto von Guericke Universität Magdeburg, Universitätsplatz 2, 39106 Magdeburg \\ Corresponding author: Silja-Katharina Rittinghaus; siljakatharina.rittinghaus@ilt.fraunhofer.de
}

\begin{abstract}
:
Lightweight titanium aluminides (TiAl, $\rho=3.9-4.1 \mathrm{~g} / \mathrm{cm} 3$ ) gain in importance as high temperature structural material. The known properties like high strength and creep resistance combined with high corrosion and wear are of continuous interest for turbomachinery applications like low pressure turbine blades. Additive manufacturing (AM) provides the possibility for near-netshape production of functional complex parts and can contribute to reduce consumption and costs of material, tooling and finishing. The typical high brittleness and oxygen affinity of TiAl cause special requirements for processing this material with AM. In this work, recent progress in Additive Manufacturing of the TiAl alloys of the nominal compositions Ti-43.5Al-4Nb-1Mo-0.1B (at.percent, TNM ${ }^{\mathrm{TM}}-\mathrm{B} 1$ ), Ti-48Al-2Cr-2Nb (at.-percent, GE4822) and Ti-45Al-2Nb-2Mn-0.8B (at.-percent, 4522XDTM) is presented. Microstructures resulting from both Laser Powder Bed Fusion (LPBF) and Direct Laser Deposition (DED) are compared with respect to the characteristics of the manufacturing processes. Hardness measurements according to Vickers are performed, and pressure strength tests are performed on selected samples. The crack-free additive manufacturing of complex geometries made of TiAl is demonstrated as well as an approach for manufacturing hybrid parts combining DED and LPBF.
\end{abstract}

\section{Introduction}

Lightweight intermetallic TiAl-based alloys can compete with Ni-based alloys in temperature ranges up to $800^{\circ} \mathrm{C}$. By providing high specific strength and creep resistance combined with good oxidation resistance they have been qualified for turbomachinery applications [1-5] and considered for part production by conventional, powder metallurgical and additive manufacturing (AM) [611]. Starting with General Electric introducing GE4822 as a structural material for GEnx-engine blades [12] and Rolls Royce using cast 4522XDTM for a number aero-engine components e.g. compressor stator vanes, blades and LP turbine blades [13], MTU Aero Engines developed an alloy called TNMTM. Manufactured by forging, it is in use since 2016, e.g. in the Pratt\&Whitney PW1100G fan engine [14]. TiAl not only provides advantageous properties but is also characterized by high room temperature brittleness and high oxidation affinity. Thus, conventional machining or welding is difficult [15-18], cost intensive and additive manufacturing becomes increasingly attractive, particularly for parts with complex inner structures. Current research includes EBM of e.g. GE4822 [9,19], Laser powder bed fusion (LPBF) of TNMTM [8,20], and Direct energy deposition (DED) of GE4822 and TNMTM $[7,10,21]$. Potential in Laser additive manufacturing is provided by the possibility to evade the necessity for a costly vacuum atmosphere and build on already 3-dimensional structures. Therefore, in the present study we aim to complete the demonstration of the feasibility to manufacture defect free parts out of the above mentioned TiAl alloys GE4822, 4522XDTM and TNMTM with both LPBF and DED. The manufacturing of test material is performed to compare the procedures and test for transferability and compatibility within the $\gamma$-TiAl system especially regarding aspects of hybrid manufacturing.

\section{Experimental}

Material

The powders used in this study and the nominal chemical composition are listed in Table I.

Table I: Chemical composition of material used in this study, values in at.-\%

\begin{tabular}{|l|l|l|l|l|l|l|l|}
\hline Alloy & Al & Nb & Mo & Cr & Mn & B & Fraction \\
\hline TNM $^{\text {TM }}$ (DED) & 43.5 & 4 & 1 & & & 0.1 & $20-90 \mu \mathrm{m}$ \\
\hline TNM $^{\text {TM }}$ (LPBF) & 43.3 & 4 & 1 & & & 0.1 & $25-63 \mu \mathrm{m}$ \\
\hline GE4822 & 48 & 2 & & 2 & & & $20-90 \mu \mathrm{m}$ \\
\hline $4522 \mathrm{XD}^{\mathrm{TM}}$ & 45 & 2 & & & 2 & 0.8 & $20-90 \mu \mathrm{m}$ \\
\hline
\end{tabular}

For LPBF, the GE4822 and 4522XD powder were sieved and the fraction $<75 \mu \mathrm{m}$ was used for the experiments. For LMD, similar cast material was used as substrate material. LBPF base-plates were made out of Ti6Al4V.

\section{DED Setup and Processing}

The LMD setup consisted of an argon purged process chamber $(\mathrm{O} 2<50 \mathrm{ppm})$ with a 3 -axis cartesian machine, a $2 \mathrm{~kW}$ diode laser type LDF 2000-30 (Laserline GmbH) with wavelengths 1025 und $1064 \mathrm{~nm}$, an OTS-5 optic (Laserline GmbH) and an induction preheating provided by a medium frequency generator MFG18 (Eldec $\mathrm{GmbH}$ ) with max. $18 \mathrm{~kW}$. The final parameters applied to material analyzed in this study are listed in Table II. 
Table II: LMD parameters finally used in this study

\begin{tabular}{|c|c|c|c|c|c|c|}
\hline Alloy & Laser power & $\begin{array}{l}\text { Spot } \\
\text { diameter }\end{array}$ & Velocity & $\begin{array}{l}\text { Hatch } \\
\text { distance }\end{array}$ & $\begin{array}{l}\text { Layer } \\
\text { thickness }\end{array}$ & Preheating \\
\hline TNM & \multirow{3}{*}{$66 \mathrm{~W}$} & \multirow{3}{*}{$0.6 \mathrm{~mm}$} & \multirow{3}{*}{$500 \mathrm{~mm} / \mathrm{min}$} & \multirow{3}{*}{$0.3 \mathrm{~mm}$} & \multirow{3}{*}{$0.25 \mathrm{~mm}$} & \multirow{3}{*}{$900^{\circ} \mathrm{C}$} \\
\hline GE4822 & & & & & & \\
\hline $4522 \mathrm{XD}$ & & & & & & \\
\hline
\end{tabular}

\section{LPBF Setup and Processing}

For LPBF experiments, a MIDI (Aconity 3D $\mathrm{GmbH}$ ) equipped with a 1kW fibre laser type YLR-1000WC, (IPG Photonics Corporation) with a wavelength of $1070 \mu \mathrm{m}$ and a galvanometric scanner type intelliSCAN30 (SCANLAB GmbH) was used. Induction heating of max. $1200^{\circ} \mathrm{C}$ was provided by a TruHeat HF 3005 (TRUMPF GmbH + Co. KG). Based on preliminary investigations a preheating temperature of $900^{\circ} \mathrm{C}$ is used. This temperature is higher than the respective brittle-to-ductile-transienttemperature (BDTT) and increases the ductility to enable crack free building of parts. The oxygen content during the process was approx. $0 \mathrm{ppm}$. An alternating hatching strategy was used. The final parameters applied to material analyzed in study are listed in Table III.

Table III: LPBF parameters finally used in this study

\begin{tabular}{|c|c|c|c|c|c|c|}
\hline Alloy & Laser power & $\begin{array}{l}\text { Spot } \\
\text { diameter }\end{array}$ & Scan speed & $\begin{array}{l}\text { Hatch } \\
\text { distance }\end{array}$ & $\begin{array}{l}\text { Layer } \\
\text { thickness }\end{array}$ & Preheating \\
\hline TNM & $200 \mathrm{~W}$ & & $1200 \mathrm{~mm} / \mathrm{s}$ & $80 \mu \mathrm{m}$ & $30 \mu \mathrm{m}$ & \multirow{3}{*}{$900^{\circ} \mathrm{C}$} \\
\hline GE4822 & \multirow{2}{*}{$175 \mathrm{~W}$} & \multirow{2}{*}{$80 \mu \mathrm{m}$} & \multirow{2}{*}{$1400 \mathrm{~mm} / \mathrm{s}$} & \multirow{2}{*}{$60 \mu \mathrm{m}$} & \multirow{2}{*}{$25 \mu \mathrm{m}$} & \\
\hline $4522 \mathrm{XD}$ & & & & & & \\
\hline
\end{tabular}

\section{Post heat treatment}

The heat treatment was performed in a KLS 05/13 Therm-Concept furnace with a maximum temperature of $1300^{\circ} \mathrm{C}$ and a continuous protective Argon stream of $300 \mathrm{~L} / \mathrm{h}$. The respective parameters for each alloy are listed in Table IV.

Table IV: Heat treatment parameters used in this study

\begin{tabular}{|l|l|l|l|}
\hline Alloy & Temperature & Duration & Cooling \\
\hline TNM & $1290^{\circ} \mathrm{C}$ & $60 \mathrm{~min}$ & Furnace cooling \\
\hline GE4822 & $1250^{\circ} \mathrm{C}$ & $240 \mathrm{~min}$ & Air cooling \\
\hline $4522 \mathrm{XD}$ & $1260^{\circ} \mathrm{C}$ & $60 \mathrm{~min}$ & Furnace cooling \\
\hline
\end{tabular}

Analysis methods

Samples were cut along the build direction $\mathrm{z}$ across the weld direction. Images of polished cross sections were taken with a LEO1455 EP (Zeiss GmbH).

Micro-hardness measurements were performed using a Leco semi-automatic Vickers tester. The testing time was $15 \mathrm{~s}$ with a test load of $300 \mathrm{~g}$. The distance between measurements was $0.5 \mathrm{~mm}$, which were performed in the middle section of each sample parallel to the build direction.

Pressure strength tests were performed with a Zwick Roell Z100 machine including a Maytec furnace with a testing speed 10-4 s-1 until break point. The testing temperature was $700^{\circ} \mathrm{C}$. The atmosphere was argon.

\section{Results}

Process evolution

\section{DED}

In Figure 1 the process evolution performed for LMD of $\gamma$-TiAl is depicted in selected examples of the produced samples. With the parameters listed in Table II, geometries with a min. width of $0.6 \mathrm{~mm}$ can be built out of the alloys TNM-B1TM, GE4822 and $4522 \mathrm{XDTM}$ without showing cracks or porosity $>0.5 \%$ in any case. The maximum build height tested is $60 \mathrm{~mm}$, the maximum width $10 \mathrm{~mm}$. 

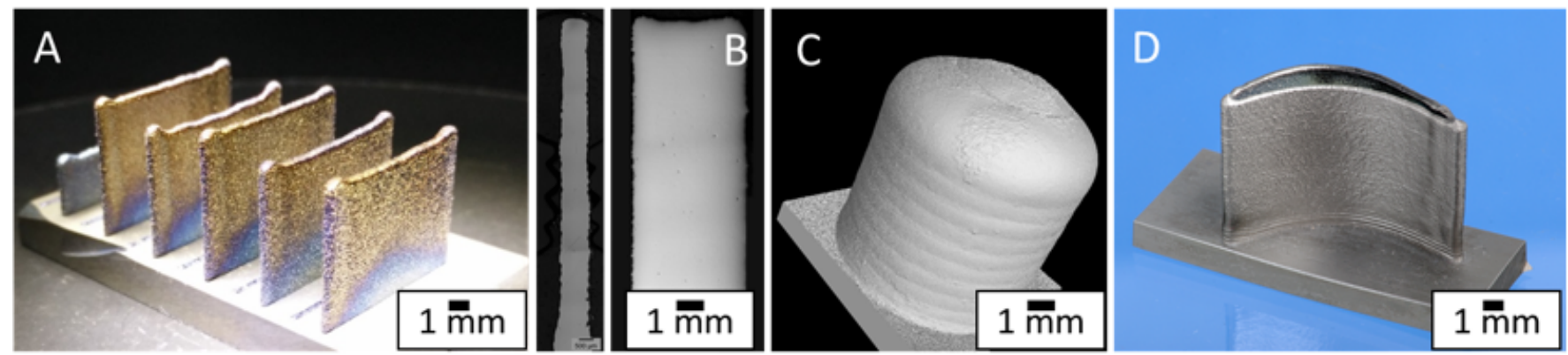

Figure 1: Process development DED, A) walls of width $0,6 \mathrm{~mm}$ (GE4822), B) cross section of walls with width 0,6 and 4 mm (TNM-B1) C) cylindrical sample, CT image D)turbine blade mock-up (GE4822)

\section{LPBF}

In [20] is demonstrated the successful build of a complete automobile turbocharger wheel out of TNMTM-B1 with LPBF. In the present study, process parameters were developed to produce equally dense and crack free parts out of GE4822 and 4522XDTM. Selected results of this study are presented in Figure 2.
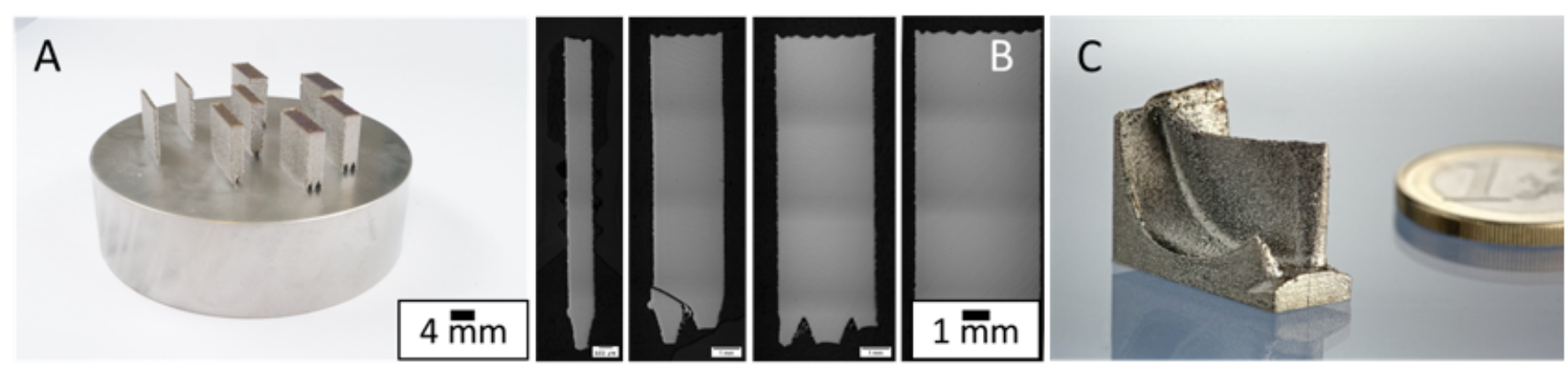

Figure 2: Process development LPBF, A) walls of $15 \mathrm{~mm} \times 10 \mathrm{~mm}$ with width $1-5 \mathrm{~mm}$ (GE4822), B) cross section of walls $15 \mathrm{~mm} \times 10 \mathrm{~mm}$ with width 1-5 $\mathrm{mm}(4522 X D)$ C) blade from automobile turbocharger wheel (GE4822)

Walls with a chosen thickness between 1 and $5 \mathrm{~mm}$ are built. The parts are crack free and show a density $>99.95 \%$. The manufacturing of complex parts is demonstrated by a segment of the geometry used in [20].

For further comparison, test samples with the width of $4 \mathrm{~mm}$ and height of $10 \mathrm{~mm}$ are selected for both processes and all alloys.

Microstructure and properties

In Figure 3 SEM images of cross sections of LAM material in their respective heat treated condition are depicted. All samples consist out of the expected [5] phases which are mainly $\gamma$-phase (dark grey) as well as lamellar $\gamma+\alpha 2$ - colonies (grey/light grey). While in DED manufactured TNMTM-material $\beta 0$-phase occurs (nearly white, Figure 3 D), in both 4522XDTM samples borides (Figure $3 \mathrm{C}, \mathrm{F}$ ) can be detected (white). 

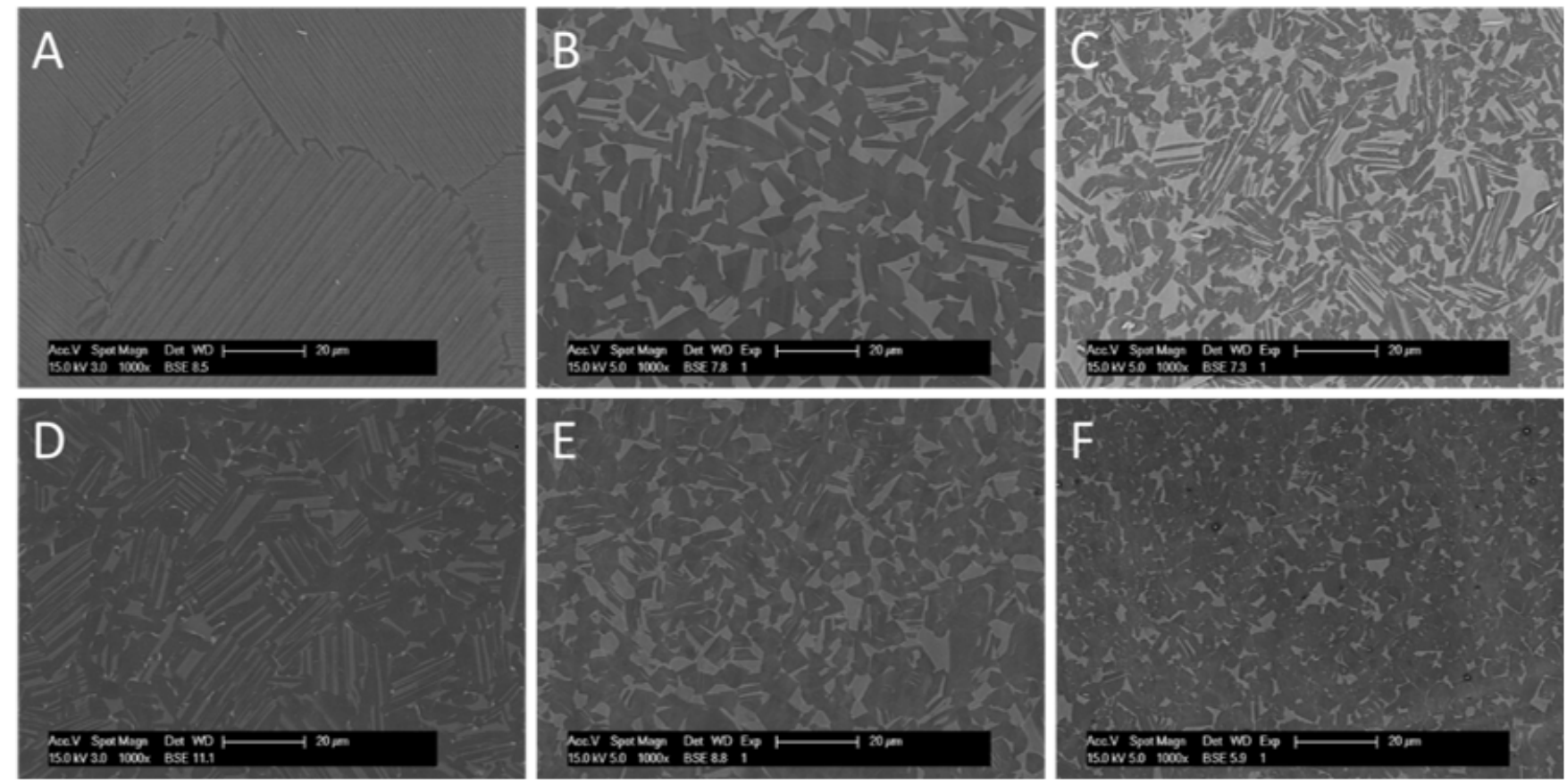

Figure 3: LAM of TNMTM (A, D), GE4822 (B,E) and 4522XDTM (C,F), A)-C): LPBF, D)-F) DED, SEM-BSE, magnification $3500 x(A, D)$ and $2000 x(B, C, E, F)$ in respectively heat treated condition

One remarkable aspect is the difference in size and distribution of microstructural features. The decreased cooling rate in DED compared to LPBF in the range of times $10 \mathrm{~K} / \mathrm{s}$ leads to a still very fine, but comparatively coarser structure. Nevertheless, after heat treatment the grain sizes appear similar for DED and LPBF in case of the GE4822 and 4522XDTM. Additionally, DED manufactured samples consequently show a higher amount of $\gamma$ phase compared to the LPBF counterparts. It is assumed, that a higher content of oxygen in DED, like e.g. reported in [7] as well as the lower Al-content stabilizes $\alpha$ and increases T $\gamma$, solv [21]. This effect is most prominent when comparing the LAM TNMTM samples. As a consequence of reaching the T $\gamma$, solv in LBPF material, $\gamma$ is soluted during heat treatment of LPBF samples. Grain growth occurs, and the final microstructure is completely lamellar. At the same time, in DED samples due to the chemical composition the heat treatment still occurs in the $(\alpha+\gamma)$-field. Grain boundaries are stabilized by unsolved $\gamma$ and $\beta$ phase. Grain growth is hindered, and unsolved primary lamellae grow in width. Because of finer secondary lamellae and a higher amount of $\alpha$, higher hardness and smaller ductility for LPBF samples is expected. Hardness measurements of all samples and alloys processed in this study are presented in Figure 4. Heat treatment results in general softening of all samples and equalizing of the respective DED and LPBF material.

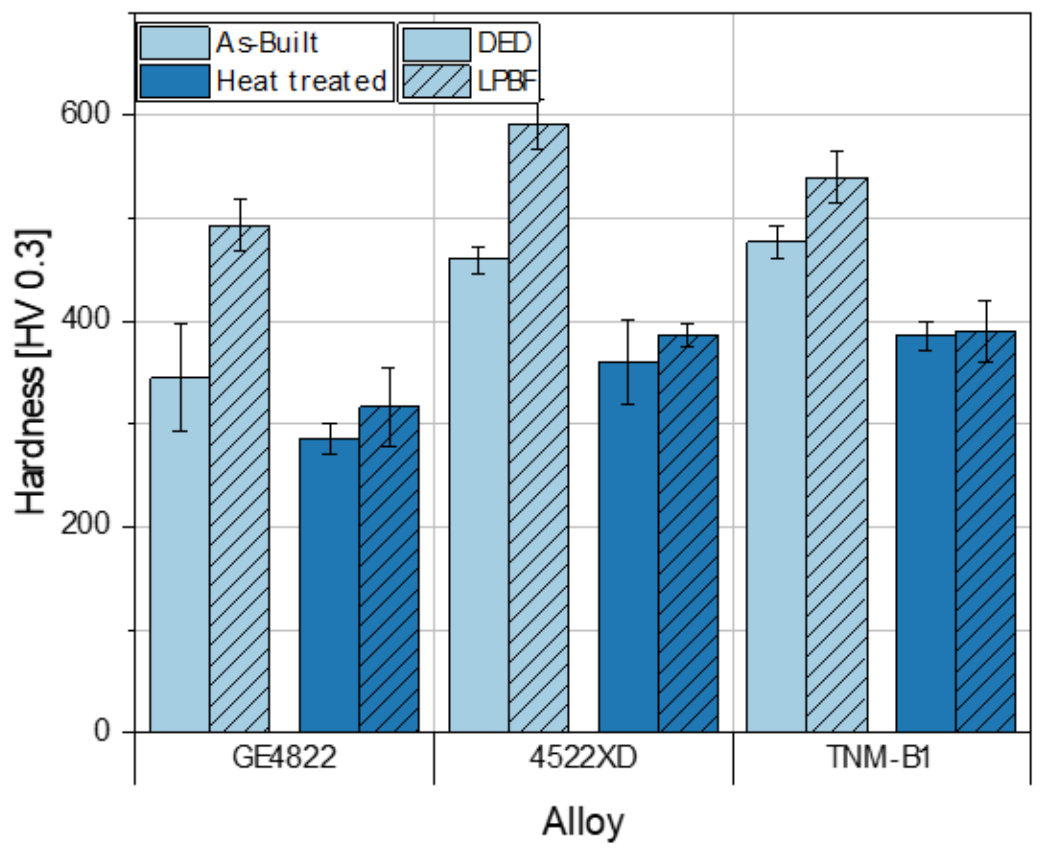


Figure 4: Hardness of LAM produced samples with and without heat treatment

In accordance with the differences in microstructure, LPBF samples tend to still show a higher hardness after heat treatment. Despite the massive grain growth in LPBF TNMTM, which would support a smaller hardness compared to DED, the completely lamellar structure seems to be dominant over the grain size. Therefore, both effects balance each other, resulting in similar hardness values and supporting the idea of combining both AM and other manufacturing processes for part production.

On selected samples, pressure strength tests were performed at $700^{\circ} \mathrm{C}$ results of which are presented in Figure 5 .

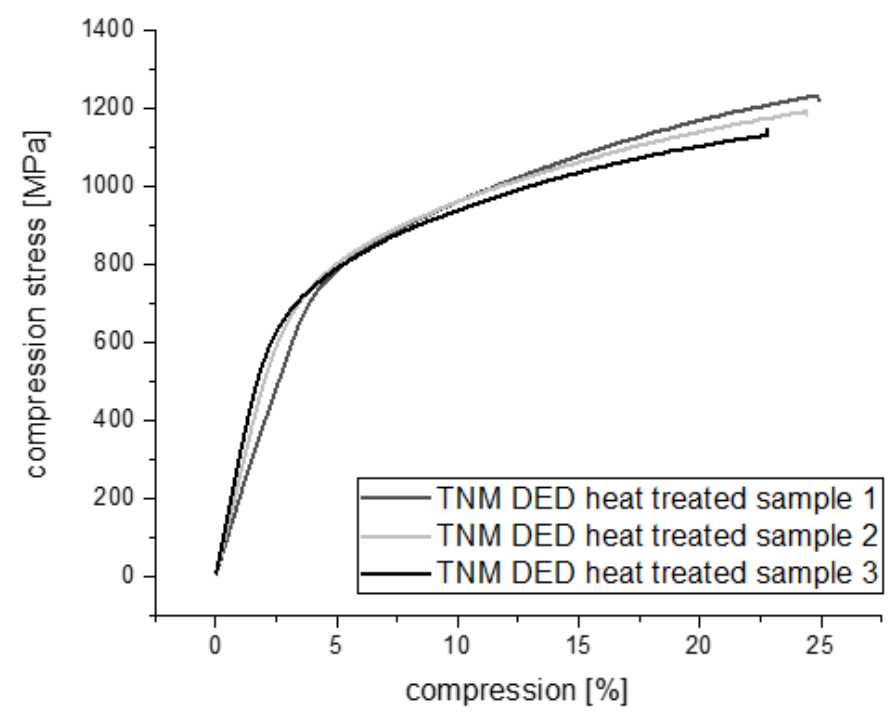

Figure 5: Compression strength test results

DED samples reach a yield strength in compression of $207 \mathrm{MPa} \pm 48$ with a compression of $0,8 \%$ in average. The maximum breaking stress in compression reaches $1180 \mathrm{MPa} \pm 44$ with a compression of 24.5. These values illustrate a low ductility of the material even at elevated temperatures and in the range of related tests at room temperature $[8,20]$. It is assumed, that further decrease in oxygen during the process chain could be favorable to increase the mechanical properties, which therefore is a remaining challenge for LAM not only of TiAl but several intermetallic materials. Tests of the other materials used in this study are on-going for direct comparison.

Outlook: Hybrid manufacturing

Similar microstructures (GE4822 and 4522XDTM) and hardness values support well the idea of hybrid manufacturing as e.g. a combination of DED for repair of otherwise produced parts or producing massive parts with a fast process for high build rates and adding near-net-shape features with a high solution afterwards. To give an example for this approach, a small part of a blade like presented in Figure 2,C, built with LBPF out of GE4822, was removed and afterwards built again with similar DED material. The results of this trial are presented in Figure 6.

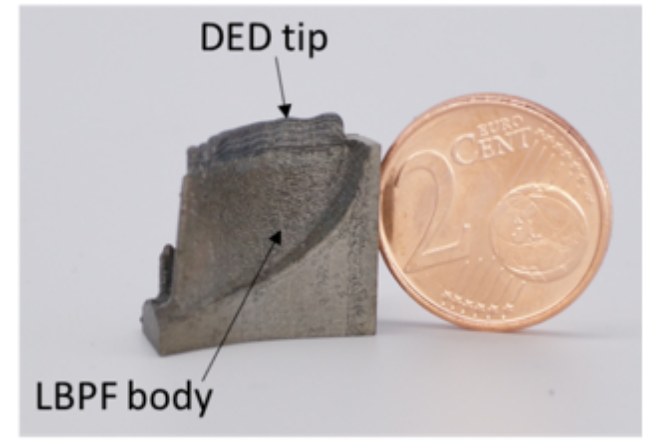

Figure 6: Demonstration of hybrid manufacturing combining LPBF and DED

\section{Conclusion}

LAM samples and parts out of TNMTM, GE4822 and 4522XDTM, produced by both DED and LPBF, were built, similarly heat treated and compared. 
i) It was demonstrated, that with nearly identical parameters and process conditions all three alloys could be processed. Solid material as well as near-net-shape geometries were built. Therefore, the developed parameter sets are likely transferable to further alloys in the TiAl-system.

ii) Despite differences in initial microstructure and local chemical composition, measurements revealed nearly similar hardness values for DED and LPBF samples. It is assumed, that compatibility of material produced by both AM and likely other processes is given, as differences diminish through heat treatment.

\section{Acknowledgements}

The authors thank especially the teams of ACCESS e.V. and Otto von Guericke Universität Magdeburg for the active support and cooperation. Part of this work was funded by the German Ministry for Education and Research BMBF, code 033RK035C.

\section{References}

[1] Appel F, Oehring M, Wagner R. Novel design concepts for gamma-base titanium aluminide alloys. Intermetallics 2000;8:1283e312.

[2] Loria E A. Quo vadis gamma titanium aluminide. Intermetallics 2001;9: 997e1001. doi:10.1016/S0966-9795(01)00064-4

[3] Loretto M H., Hu D., Li Y G.: Microstructural studies on some ordered Ti-based alloys. Intermetallics 2000;8:1243e9.

[4] Kothari, K., Radhakrishnan, R. u. Wereley, N. M.: Advances in gamma titanium aluminides and their manufacturing techniques. Progress in Aerospace Sciences 55 (2012), S. 1-16

[5] Appel F, Paul, Jonathan David Heaton, Oehring M. Gamma titanium aluminide alloys: Science and technology. Weinheim, Germany: Wiley-VCH; 2011.

[6] Aguilar J, Schievenbusch A, Kättlitz O. Investment casting technology for production of TiAl low pressure turbine blades Process engineering and parameter analysis. Intermetallics 2011;19(6):757-61.

[7] Rittinghaus S-K, Hecht U, Werner V, Weisheit A. Heat treatment of laser metal deposited TiAl TNM alloy. Intermetallics 2018;95:94-101.

[8] Gussone J, Hagedorn Y-C, Gherekhloo H, Kasperovich G, Merzouk T, Hausmann J. Microstructure of $\gamma$-titanium aluminide processed by selective laser melting at elevated temperatures. Intermetallics 2015;66:133-40.

[9] Biamino S, Penna A, Ackelid U, Sabbadini S, Tassa O, Fino P et al. Electron beam melting of Ti-48Al-2Cr-2Nb alloy: Microstructure and mechanical properties investigation. Intermetallics 2011;19(6):776-81.

[10] Thomas M, Malot T, Aubry P. Laser Metal Deposition of the Intermetallic TiAl Alloy. Metall and Mat Trans A 2017;192(193):519.

[11] Clemens H, Mayer S. Pulvermetallurgie von intermetallischen Titanaluminiden. BHM (2015) Vol. 160 (10-11): 513-516. doi:10.1007/s00501-015-0411-0

[12] Clark, S. F.: 787 propulsion system. AERO Magazine, quarter $3, \quad 2012 . \quad$ Available http://www.boeing.com/commercial/aeromagazine/articles/2012_q3/index.html

[13] Voice W. The future use of gamma titanium aluminides by Rolls-Royce. Aircraft Engineering and Aerospace Technology 1999, Vol. 71 Issue: 4, pp.337-340. doi:10.1108/00022669910371031

[14] Janschek P. Wrought TiAl blades. Conference MEFORM 2015: Light Metals - Forming Technologies and Further Processing. Materials Today: Proceedings 2S (2015) S92-S97

[15] M.F. Arenas, V.L. Acoff, The effect of postweld heat treatment on gas tungsten arc welded gamma titanium aluminide, Scripta Mater. 46 (3) (2002) 241-246.

[16] D. Herrmann, F. Appel, Diffusion bonding of $\gamma(\mathrm{TiAl})$ alloys: influence of composition, microstructure, and mechanical properties, Metall. Mater. Trans. A 40 (8) (2009) 1881-1902.

[17] K. Hauschildt, A. Stark, U. Lorenz, N. Schell, T. Fischer, M. Blankenburg, et al., Diffusion brazing of $\gamma$-TiAl-alloys: investigations of the joint by electron microscopy and high-energy X-ray diffraction, MRS Proc. 1516 (2013) 319.

[18] Castellanos, S., Cavaleiro, A., Jesus, A. de, Neto, R., \& Alves, J. L. (2019). Machinability of titanium aluminides: A review. Proceedings of the Institution of Mechanical Engineers, Part L: Journal of Materials: Design and Applications, 233(3), $426-451$. https://doi.org/10.1177/1464420718809386

[19] Jüchter V. Grundlagen des Selektiven Elektronenstrahlschmelzens von Titanaluminiden. January 2019, Doctoral Thesis.

[20] Vogelpoth A, Rittinghaus S-K, Schleifenbaum H. Laser additive manufacturing of titanium aluminides for turbomachinery applications. To be published in: Proceedings of ASME Turbo Expo 2019: Turbomachinery Technical Conference and Exposition GT2019, June 17-21, 2019, Phoenix, Arizona, USA

[21] Clemens, H. Boeck, B., Wallgram, W., Schmoelzer, T., Droessler, L. M., Zicker, G. A., Leitner, H. and Otto, A.: Experimental studies and thermodynamic simulations of phase transformations in Ti-(41-45)Al-4Nb-1Mo-0.1B alloys. Mater. Res. Soc. Symp. Proc. 1128, U03 (2009). 